\title{
Luiz Gama, \\ contemptor de nossas falsas elites
}

Fábio Konder Comparato

D URANTE muito tempo, historiadores e sociólogos consideraram ter havido um claro contraste entre a escravidão de africanos nos Estados Unidos e no Brasil. Enquanto lá os escravos foram tratados cruelmente, aqui os cativos receberam tratamento benigno, senão francamente protetor.

A meu ver, na origem dessa suposta contradição de atitudes, encontramos uma diferença radical de mentalidades. Os americanos não costumam dissimular suas convicções, e dizem francamente o que pensam. Nós, ao contrário, timbramos em proclamar nossos bons sentimentos em relação aos pobres e infelizes.

Sob esse aspecto, encarnamos à perfeição o poeta fingidor de Fernando Pessoa. Fingimos tão completamente, que chegamos por fim a nos convencer de nossa "índole reconhecidamente compassiva e humanitária", como afirmou o autor do único tratado jurídico sobre a escravidão brasileira. ${ }^{1}$ Aliás, na Exposição Internacional de Paris de 1867, o nosso governo informava, oficialmente, que "os escravos são tratados com humanidade e são em geral bem alojados e alimentados... O seu trabalho é hoje moderado... ao entardecer e às noites eles repousam, praticam a religião ou vários divertimentos". ${ }^{2}$

Nesse contexto nacional de permanente autoelogio coletivo, a personalidade de Luiz Gama, retratada neste livro muito bem organizado pela professora Lígia Fonseca Ferreira, aparece como realmente excepcional. O menino negro,

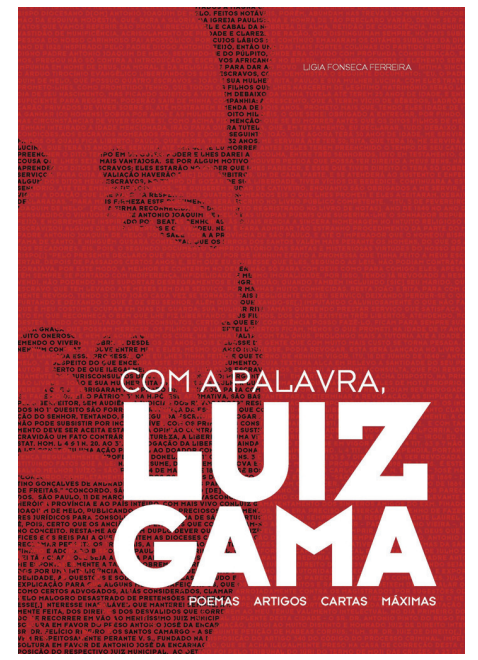

FERREIRA, L F. Com a palavra, Luiz Gama-Poema, artigos, cartas, máximas. São Paulo: Imprensa Oficial, 2011.

vendido como escravo pelo próprio pai quando tinha dez anos, tendo aprendido a ler e escrever somente aos dezessete anos, tornou-se um intelectual apurado e o maior advogado de escravos que este país conheceu. Praticamente sozinho, logrou livrar do cativeiro ilegal mais de quinhentos negros - fato sem precedentes na história mundial da advocacia. Mas, sobretudo, Luiz Gama, muito mais do que qualquer abolicionista brasileiro, não hesitou em desmascarar pela imprensa - o grande instrumento de contrapoder da época - a falsidade de nossas pretensas elites.

Gama escolheu como principais alvos de seus ataques desmascaradores os dois grupos que mais se distinguiram no tris- 
te papel de legitimar a escravidão negra: os clérigos e os magistrados. ${ }^{3}$

Já no século XVI, os jesuítas de Angola distinguiram-se na coordenação do tráfico negreiro de Angola para o Brasil. À ordem de cessação desse comércio de carne humana, baixada pelo Geral da Companhia em 1590, os padres de Angola responderam que "não é escandaloso de pagar as nossas dívidas em escravos, pois eles são a moeda corrente no país, assim como o ouro e a prata o são na Europa e o açúcar no Brasil". ${ }^{4}$

No curso dos séculos seguintes, várias ordens religiosas passaram a possuir grandes fazendas, onde acumulavam milhares de escravos. Em algumas delas, instituíram-se criatórios de escravos. $\mathrm{O}$ norte-americano Thomas Ewbank, que visitou o Brasil em meados do século XIX, informou que num "grande estabelecimento" que a ordem beneditina possuía na Ilha do Governador, no Rio, "numerosas gerações de rapazes e moças de cor são lá criadas até terem idade suficiente para serem enviadas ao trabalho nas propriedades do interior". ${ }^{5}$

$\mathrm{Na}$ verdade, os escravos eram também numerosos dentro dos próprios conventos de frades e freiras. Em meados do século XVIII, no Convento do Desterro da Ordem das Suplicantes, em Salvador, 75 religiosas eram servidas por 400 escravas. $^{6}$

Fato é que a Igreja Católica não manifestou, até as vésperas do 13 de maio, o menor empenho pela abolição da escravatura.

Ao ser promulgada a Lei do Ventre Livre em 1871, D. Pedro Maria de Lacerda, bispo do Rio de Janeiro, em linguagem retorcida, fez questão de se pronunciar contra a abolição total e imediata. "Os revolucionários que profanem o nome da liberdade", escreveu ele em carta pastoral. "Nós, porém, mostremos que por ela, quando justa, como em nosso caso, sabemos fazer algum sacrifício, principalmente sendo este compensado por bem de ordem mais elevada, sem exclusão dos bens materiais e pecuniários." No Pará, na mesma ocasião, o bispo d. Antonio de Macedo Costa dirigiu enérgico protesto contra aquela Lei ao presidente da província, arguindo que se tratava de violação dos direitos da Igreja por uma medida "irregular e anticanônica"?

Quanto aos magistrados, as providências de justiça que deles podiam esperar os cativos eram praticamente nulas; não só pelo velho costume da corrupção, mas também por serem eles, quase sem exceção, proprietários de escravos.

A corrupção geral da Justiça no Brasil foi atestada pela maior parte dos viajantes estrangeiros.

No relato de sua viagem ao Rio de Janeiro e a Minas Gerais, Saint-Hilaire observou: "Em um país no qual uma longa escravidão fez, por assim dizer, da corrupção uma espécie de hábito, os magistrados, libertos de qualquer espécie de vigilância, podem impunemente ceder às tentações". ${ }^{8}$

No mesmo sentido, John Luccock: "Na realidade parece ser de regra que no Brasil toda a Justiça seja comprada. Esse sentimento se acha por tal forma arraigado nos costumes e na maneira geral de pensar, que talvez ninguém o considere danoso (a tort); por outro lado, protestar contra a prática de semelhante máxima pareceria não somente ridículo, como serviria apenas para provocar a completa ruína do queixoso".

E Charles Darwin, por ocasião da estadia do Beagle em nosso país: "Não 
importa o tamanho das acusações que possam existir contra um homem de posses, é seguro que em pouco tempo ele estará livre. Todos aqui podem ser subornados". 10

Compreende-se, assim, o grau de destemor e pertinácia, demonstrados por Luiz Gama, quando se opôs sem meias palavras, em mais de uma ocasião, a juízes pusilânimes e servis diante de senhores de escravos. ${ }^{11}$

Ao assim proceder, seguiu ele as lições de Cícero no De Oratore, sobre a conduta e as qualidades intrínsecas daquele que pleiteia no foro ou na tribuna política. Em primeiro lugar, o que o grande romano chamou de acumen, vale dizer a argúcia em argumentar. Em segundo lugar, a diligentia, ou seja, o zelo e aplicação constantes na defesa das causas confiadas ao seu patrocínio. Além disso, o probare, ou destreza em provar a verdade, aliado ao conciliare, ou arte de atrair simpatia. Por fim, o movere, isto é, a capacidade de suscitar a emoção no espírito dos ouvintes.

Vamos, portanto, ler os libelos contidos neste livro, como se estivéssemos a ouvir o maior defensor de escravos que este país jamais conheceu.

\section{Notas}

1 Dr. Agostinho Marques Perdigão Malheiro, A Escravidão no Brasil - Ensaio Histórico-Jurídico-Social. Rio de Janeiro: Typographia Nacional, 1866. t.II, p.61 e 114.

2 Citado por Celia Maria Marinho de Azevedo, Abolicionismo: Estados Unidos e Brasil, uma história comparada (século XIX). São Paulo: Annablume, 2003. p.63.

3 Em relação aos primeiros, leia-se, nas p.95 e ss., o artigo "Apontamentos Bio- gráficos", publicado no Radical Paulistano, onde é descrita sarcasticamente a pessoa de um bispo diocesano de São Paulo. Quanto aos magistrados, leiam-se todos os artigos de jornal reproduzidos nas p.101 a 129.

4 Cf. História da Igreja no Brasil. Petrópolis: Vozes, 1979. t.2, p.200.

5 Thomas Ewbank, Vida no Brasil. São Paulo: Editora da Universidade de São Paulo; Livraria Itatiaia, 1976. p.102.

6 Cf. Pedro Calmon, História social do Brasil. São Paulo: Companhia Editora Nacional, s. d. $1^{\circ}$ t., p.74.

7 História da Igreja no Brasil. Petrópolis: Vozes, 1980. t.II/2, p.277-8.

8 Auguste de Saint-Hilaire, Viagem pelas províncias do Rio de Janeiro e Minas Gerais. São Paulo: Editora da Universidade de São Paulo; Livraria Itatiaia, 1975. p.157.

9 Notas sobre o Rio de Janeiro e partes meridionais do Brasil, São Paulo: Editora da Universidade de São Paulo; Livraria Itatiaia, 1975. p.321.

10 O Diário do Beagle. Editora UFPR, 2006. p.100.

11 Leia-se o artigo "O Novo Alexandre", às p.121 e ss.

Fábio Konder Comparato é professor emérito da Faculdade de Direito da Universidade de São Paulo, doutor Honoris Causa da Universidade de Coimbra.

@ - fkcomparato@gmail.com

O texto foi publicado originalmente como prefácio à obra resenhada. 

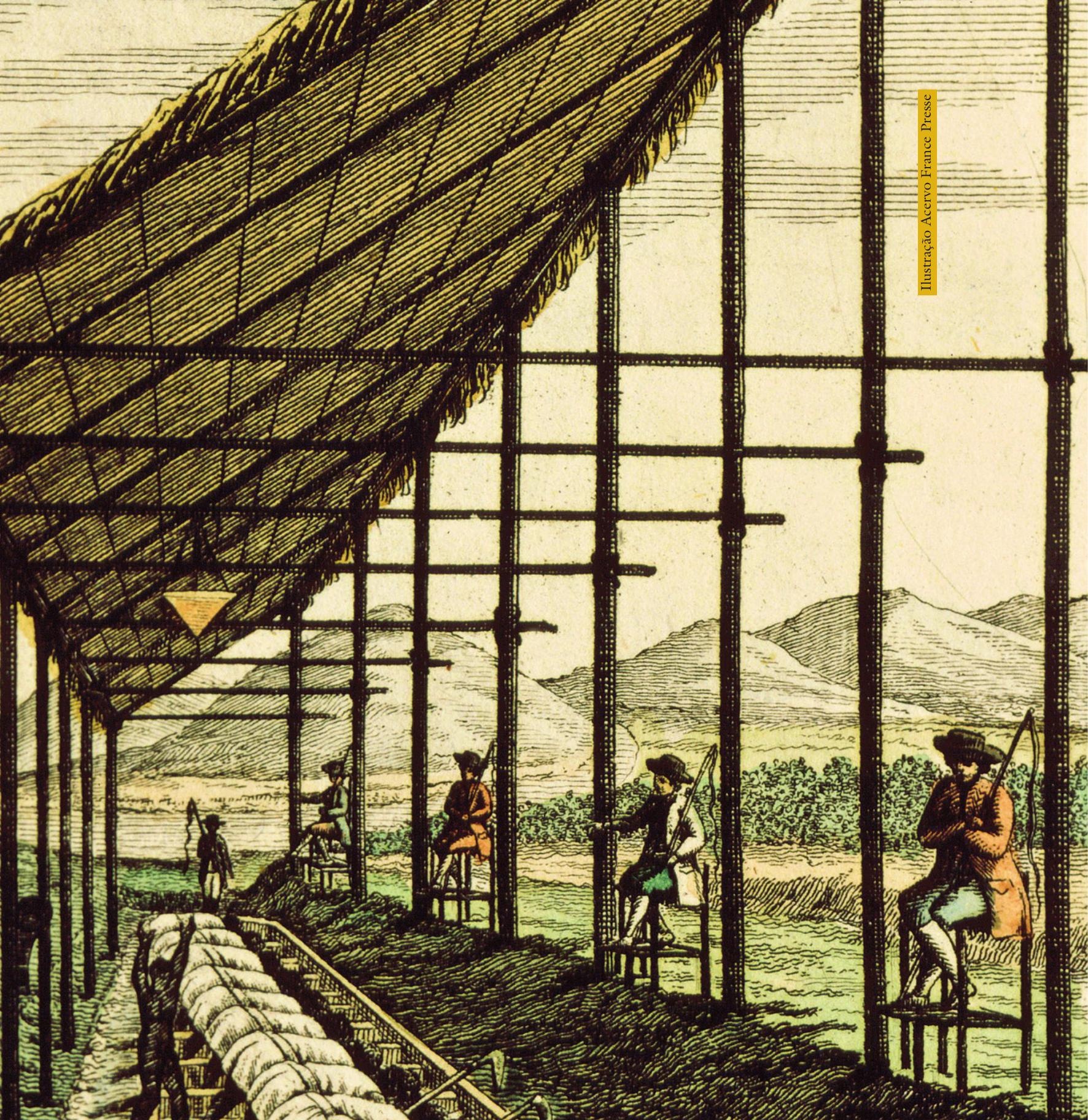

\section{Sces}

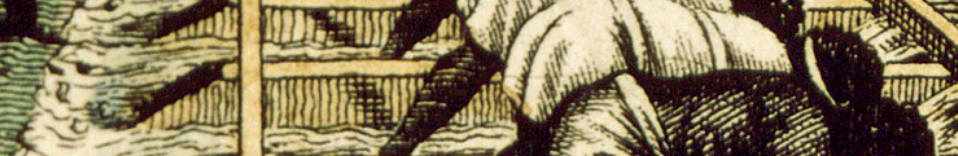

00

C

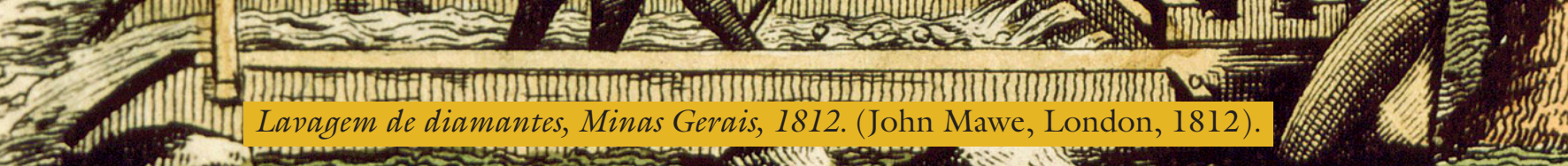
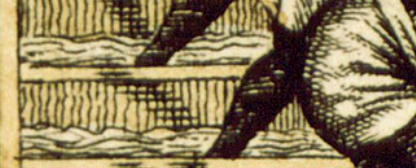

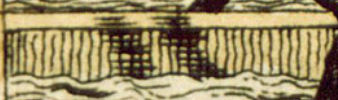

1)

(a)

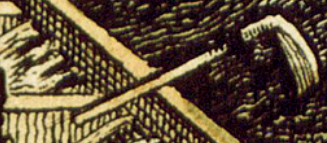

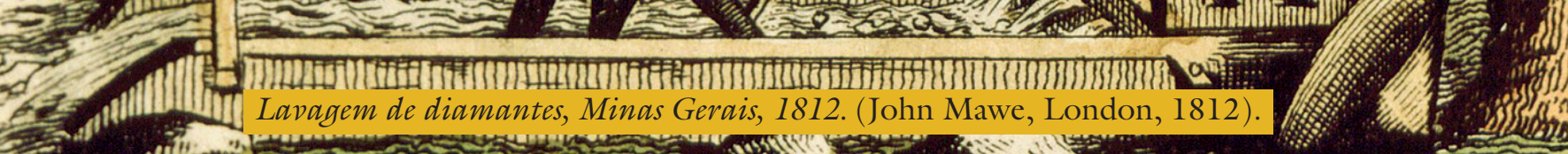

